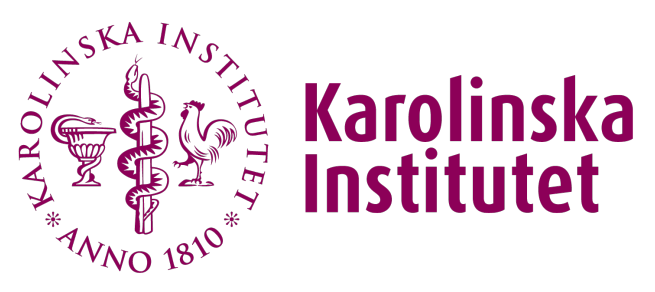

\title{
Karolinska Institutet
}

http://openarchive.ki.se

This is a Peer Reviewed Manuscript version of the following article, accepted for publication in Genes and Immunity.

\section{Age-dependent variation of genotypes in $\mathrm{MHC}$ II transactivator gene (CIITA) in controls and association to type 1 diabetes}

Gyllenberg, Alexandra; Asad, Samina; Piehl, Fredrik; Swanberg, Maria; Padyukov, Leonid; van Yserloo, Brian; Graham, Jinko; Rutledge, Elizabeth; Orho-Melander, Marju; Lindholm, Eero; Graff, Caroline; Forsell, Charlotte; Åkesson, Karin; Landin-Olsson, Mona; Carlsson, Annelie; Forsander, Gun; Ivarsson, Sten; Larsson, Helena; Alfredsson, Lars; Åkesson, Kristina; Olsson, Tomas; Kockum, Ingrid; Lindblad, Bengt; Ludvigsson, Johnny; Marcus, Claude; Lernmark, Åke; McNeney, Brad

Genes Immun. 2012 Dec;13(8):632-40.

http://doi.org/10.1038/gene.2012.44

http://hdl.handle.net/10616/41464

If not otherwise stated by the Publisher's Terms and conditions, the manuscript is deposited under the terms of the Creative Commons Attribution-NonCommercial-NoDerivatives License (http://creativecommons.org/licenses/by-nc-nd/4.0/), which permits non-commercial re-use, distribution, and reproduction in any medium, provided the original work is properly cited, and is not altered, transformed, or built upon in any way. 


\section{(19) \\ Karolinska Institutet}

This is an author produced version of a paper published in Genes and Immunity. This paper has been peer-reviewed but does not include the final publisher proof-corrections or journal pagination.

Citation for the published paper:

Genes and Immunity (2012) 13, 632-640

Age-dependent variation of genotypes in MHC II transactivator gene (CIITA) in controls and association to type 1 diabetes.

\section{Gyllenberg, Alexandra et al [27 authors]}

URL: http: //dx.doi.org/10.1038/gene.2012.44

Access to the published version may require subscription.

Published with permission from: NPG 


\section{Age Dependent Variation of Genotypes in MHCII Transactivator gene (CIITA) in Controls and Association to Type 1 Diabetes}

Short title: Age dependent variation in CIITA

Alexandra Gyllenberg ${ }^{1}$, Samina Asad $^{1}$, Fredrik Piehl ${ }^{1}$, Maria Swanberg $^{2}$, Leonid Padyukov $^{3}$, Brian Van Yserloo ${ }^{4}$, Elizabeth A. Rutledge ${ }^{5}$, Brad McNeney ${ }^{6}$, Jinko Graham ${ }^{6}$, Marju OrhoMelander $^{7}$, Eero Lindholm ${ }^{7}$, Caroline Graff ${ }^{8,9}$, Charlotte Forsell ${ }^{8,9}$, Karin Åkesson ${ }^{10}$, Mona Landin-Olsson $^{11}$, Annelie Carlsson ${ }^{12}$, Gun Forsander ${ }^{13}$, Sten A. Ivarsson ${ }^{14}$, Helena Larsson ${ }^{14}$, Bengt Lindblad $^{15}$, Johnny Ludvigsson ${ }^{16}$, Claude Marcus ${ }^{17}$, Åke Lernmark ${ }^{14,18}$, Lars Alfredsson $^{19}$, Kristina Åkesson ${ }^{20,21}$, Tomas Olsson ${ }^{1}$, Ingrid Kockum ${ }^{1}$

for the Swedish Childhood Diabetes Study Group ${ }^{*}$, the Diabetes Incidence in Sweden Study Group*, and the Better Diabetes Diagnosis Study group* .

1. Neuroimmunology Unit, Dep. of Clinical Neuroscience, Karolinska Institutet, Stockholm Sweden.

2. Neurodegeneration and Inflammation Genetics Unit, Dep. of Experimental Medical Science, Lund University, Sweden

3. Rheumatology Unit, Dep. of Medicine, Karolinska Institutet, Stockholm Sweden 4. Molecular and Genetics Core, Diabetes Endocrinology Research Center, University of Washington, Seattle, WA, United States

5. Salish Kootenai College, Pablo, MT, United States

6. Dep. of Statistics and Actuarial Science, Simon Fraser University, Burnaby, Canada.

7. Diabetes and Cardiovascular Disease, Genetic Epidemiology, Dep. of Clinical Sciences, Skåne University Hospital, Lund, Sweden 
8. Dep. of Neurobiology, Care Sciences and Society, Karolinska Institutet, Stockholm, Sweden

9. Dep. of Geriatric Medicine, Karolinska University Hospital Huddinge, Stockholm, Sweden 10. Dep. of Pediatrics, Ryhov County Hospital, Jönköping, Sweden

11. Dep. of Medicine, Skåne University Hospital, Lund, Sweden.

12. Dep. of Pediatrics, Skåne University Hospital, Lund, Sweden

13. Dep. of Pediatrics, The Queen Silvia Children's Hospital, Sahlgrenska/Ostra University Hospital, Göteborg, Sweden

14. Dep. of Clinical Sciences, Skåne University Hospital, Malmö, Sweden

15. Dep. of Pediatrics, Institute of Clinical Science, Sahlgrenska Academy, University of Gothenburg, Gothenburg, Sweden

16. Division of Pediatrics and Diabetes Research Center, Dep. of Clinical and Experimental Medicine, Linköping University, Linköping, Sweden

17. Division of Pediatrics, Dep. of Clinical Science, Intervention and Technology, Karolinska Institutet, Stockholm, Sweden

18. Dep. of Medicine, University of Washington, Seattle, WA. United States

19. Dep. of Environmental Medicine, Karolinska Institutet, Stockholm Sweden.

20. Clinical and Molecular Osteoporosis Research Unit, Dep. of Clinical Sciences, Lund University, Sweden

21. Dep. of Orthopaedics, Skåne University Hospital, Malmö, Sweden

\footnotetext{
* Members of the Swedish Childhood Diabetes Study Group, the Diabetes Incidence in Sweden Study Group and the Better Diabetes Diagnosis Study group are listed in supplementary material.
} 
Corresponding author:

Alexandra Gyllenberg

Dep. of Clinical Neurosciences

Karolinska Insitutet

Centre for Molecular Medicine, L8:05

Karolinska University Hospital

S171 76 Stockholm

Sweden

Tel: +46-8-51776258

Fax: +46-8-51770885

e-mail: alexandra.gyllenberg@ki.se 


\section{$\underline{\text { Abstract }}$}

The Major Histocompatibility Complex Class II Transactivator (CIITA) gene (16p13) has been reported to associate with susceptibility to multiple sclerosis, rheumatoid arthritis and myocardial infarction, recently also to celiac disease at genome wide level. However, attempts to replicate association have been inconclusive. Previously, we have observed linkage to the CIITA region in Scandinavian type 1 diabetes families.

Here we analyze five Swedish type 1 diabetes cohorts and a combined control material from previous studies of CIITA. We investigate how the genotype distribution within the CIITA gene varies depending on age, and the association to type 1 diabetes.

Unexpectedly we find a significant difference in the genotype distribution for markers in CIITA (rs11074932, $\mathrm{p}=4 \times 10^{-5}$ and $\mathrm{rs} 3087456, \mathrm{p}=0.05$ ) with respect to age, in the collected control material. This observation is replicated in an independent cohort material of about 2000 individuals $(\mathrm{p}=0.006, \mathrm{p}=0.007)$.

We also detect association to type 1 diabetes for both markers, rs11074932 $(\mathrm{p}=0.004)$ and rs3087456 $(\mathrm{p}=0.001)$ after adjusting for age at sampling. The association remains independent of the adjacent type 1 diabetes risk gene CLEC16A. Our results indicate an age dependent variation in CIITA allele frequencies, a finding of relevance for the contrasting outcomes of previously published association studies.

\section{$\underline{\text { Keywords }}$}

Type 1 diabetes (T1D); CIITA; autoimmunity; association, age

\section{$\underline{\text { Introduction }}$}

Type 1 diabetes (T1D) is a multifactorial disease where a number of genes are thought to be involved in regulating disease susceptibility. The major histocompatibility complex (MHC) is 
known to be the major T1D susceptibility locus, accounting for approximately half of the genetic susceptibility to T1D ${ }^{1}$. The MHC region is thought to contain several susceptibility genes with two of the major ones being $D R B 1$ and $D Q B 1^{1}$ in the MHC class II (MHCII) region. In the Caucasian population, there are two major susceptibility haplotypes for T1D, $D R B 1 * 03-D Q A 1 * 05: 01-D Q B 1 * 02: 01$ and $D R B 1 * 04-D Q A 1 * 03: 01-D Q B 1 * 03: 02$, and one protective haplotype, $D R B 1 * 15-D Q A 1 * 01: 02-D Q B 1 * 06: 02^{2,3}$.

The regulation of the MHCII genes is mainly at the transcriptional level, and one of the crucial factors is the class II transactivator, encoded by the CIITA gene (16p13). The CIITA protein is a non-DNA binding co-activator which acts as a platform for the assembly of transcription factors that bind to MHC II promoters and control transcription ${ }^{4,5}$. CIITA is regarded as the master control factor for the expression of MHCII genes ${ }^{6}$, and the lack of CIITA expression leads to an almost complete lack of MHCII expression ${ }^{7}$. Four independent and cell type specific CIITA promoters (PI-PIV) have been identified in humans ${ }^{8}$. Promoter I (PI) mainly controls CIITA expression in myeloid dendritic cells and macrophages, while PIII is active in B-cells, activated T cells and plasmacytoid dendritic cells and the PIV promoter regulates IFN $\gamma$-inducible CIITA expression in cells of non-hematopoetic origin and in thymic epithelium ${ }^{9}$. The function of the PII promoter in humans has not yet been fully characterised $^{8}$.

Since CIITA has a unique role in the control of MHC II expression and the MHC II locus is the major genetic determinant for susceptibility to autoimmune diseases, CIITA is an interesting candidate gene in the study of autoimmune diseases like T1D ${ }^{10}$. Previously, we found genome-wide significant linkage on chromosome 16 in the region of CIITA to T1D (LOD=3.7), among T1D patients who also carry the $D R B 1 * 03$ and $D R B 1 * 04$ alleles ${ }^{11}$. The HLA association to T1D is also know to vary with age at onset, such that the association is stronger in younger patients compare to older ${ }^{3,12,13}$. 
Genome wide significant association to celiac disease has recently been reported for markers in the CIITA gene ${ }^{14}$. In addition, increased susceptibility to myocardial infarction (MI), rheumatoid arthritis (RA) and multiple sclerosis (MS) has been demonstrated for a polymorphism (rs3087456) in the $5^{\prime}$ region of type III CIITA ${ }^{15}$. However, this association has not always been replicated in later studies, and the outcome of the analysis is varying depending on which control group that has been used.

In this study, we test the hypothesis that CIITA is a T1D susceptibility gene. In addition, we investigate if the allele distribution in the gene varies depending on age, and how this may affect the evidence for association.

\section{$\underline{\text { Results }}$}

\section{Primary association to T1D in DISS2}

The tag SNPs described under methods were first genotyped in the DISS2 material, a T1D cohort consisting of DNA samples from 586 incident T1D patients and 836 controls ${ }^{16}$. Association was found in the area between PI and PIII. Five markers were added upstream of the PI promoter to better define the associated region in CIITA. One extra marker was also added in the CLEC16A gene, which is a known T1D susceptibility gene which maps close to CIITA $^{17}$, in order to exclude that association to T1D in the CIITA gene was due to LD with this gene. The initial analyses indicated that several of the SNPs were associated to T1D with the most significant association being to rs11074932 (S1). After correcting for multiple testing, only rs11074932 remained significant.

\section{Age stratification}

Due to the inconclusive results when trying to replicate earlier association in the area, and different outcome depending on what control group that was used, we wanted to investigate if 
the age among the controls could have an effect on the association. The same three markers (rs11074932, rs3087456 and rs4774) used in the combined T1D study below was investigated. Control cohorts were collected as described in the methods section, and a test for trend showed that there is a significant trend where the frequency of the genotypes changes over age for two of the markers (rs11074932, $\left.\mathrm{p}=4 \times 10^{-5} ; \mathrm{rs} 3087456, \mathrm{p}=0.05\right)$ among the controls (figl). For both markers the frequency of the major allele homozygote is increasing with age. The rs3087456 marker is significant only when the oldest age group (over 75 years of age) is included in the analysis. It should be noted that this group consist of several autopsy cases from a brain bank originally included in the Alzheimer's disease control group. No age dependent effect was evident for the rs4774 marker.

\section{Replication of age variation in an independent population based cohort material}

The same markers in the CIITA gene were investigated in two cohorts of 25 - and 75 year old women (PEAK and OPRA), respectively. Here we could confirm the significant variation in genotype for marker rs11074932 $(\mathrm{p}=0.006)$ and $\mathrm{rs} 3087456(\mathrm{p}=0.007)$ with the minor allele homozygote genotype frequency decreasing with age. Additionally, an earlier undiscovered variation could also be seen for the rs 4774 marker $(\mathrm{p}=0.03)$, but here the minor allele is instead increasing with age (fig2 and table 1).

\section{Age corrected association to type 1 diabetes in combined material}

To increase power to detect association to T1D we combined cohorts from five T1D casecontrol studies and corrected for age at sampling using logistic regression. Due to the big discrepancies in age between the T1D cases and the other control cohorts, only T1D cohorts were included in this analysis. 
Four SNPs (rs11074930, rs11074932, rs3087456 and rs4774) were chosen on the basis that they either had remained significant after correcting for age by matching each case to two controls in an initial analysis in a smaller (DISS2) cohort (rs11074930, rs11074932) (S1), or been found associated to autoimmune disease in earlier publications (rs3087456, rs4774) ${ }^{15}$, ${ }^{18-20}$. Rs 11074930 was found to deviate from Hardy-Weinberg equilibrium in a section of the control population and was discarded from further studies. Two markers showed some association (rs11074932 p=0.004 and rs3087456 p=0.001) (table 2) after correcting for age in the combined cohorts of T1D.

An age-stratified meta-analysis was performed for the associated markers to get an overview of the influence of different age-groups and clarify the association. Only individuals under 40 years of age were included in this analysis since the majority of the patient falls into this group. We find that for both rs11074932 and rs3087456, heterozygotes are negatively associated, while major allele homozygotes are positively associated with T1D (fig3).The association of CIITA SNPs to T1D was independent of CLEC16A, a nearby gene which is an established T1D locus $^{21}$, as association to CIITA SNPs remained after adding CLEC16A marker rs 12708716 to the logistic regression model in the DISS2 cohort. In addition, an LD plot of the area was made in the DISS2 cohort demonstrating that the rs12708716 SNP in CLEC16A is not in LD with any of our typed SNPs (fig4). We also tested whether gender would affect the association, and added gender as a covariate in the logistic regression model. This did not alter the association.

\section{Interaction analysis with HLA}

We also investigated if there was an interaction between T1D HLA risk alleles and CIITA. Since CIITA is a key protein in the control of expression of MHC class II alleles and we have previous findings of increased linkage in $D R B 1 * 03 / D R B 1 * 04$ positive patients in this region 
of chromosome $16^{11}$, we wanted to further investigate the role of interaction between CIITA and HLA DRB 1. Interaction analyses on both the additive and multiplicative scale was performed. These analyses were done for presence of minor allele compared to major allele homozygotes. For both associated markers (rs11074932 and rs3087456) the results showed that there is a significant additive interaction for major allele homozygotes and absence of $D R B 1 * 15$ in relation to T1D, but not in any of the other HLA types. There was no interaction on the multiplicative scale (data not shown). This means that individuals risk for T1D associated with the joint lack of the protective $D R B 1 * 15$ allele and presence of major allele homozygotes for any of these two SNPs are greater than the sum of the risk associated with $D R B 1 * 15$ and CIITA SNPs individually (fig5). The analysis shows that the association is depending on the absence of $D R B 1 * 15$, which is not unexpected since the majority of T1D cases are $D R B 1 * 15$ negative and $D R B 1 * 15$ is known as a strong protective factor for T1D. The proportion of T1D is higher among DR15 negative individuals for major allele positive compared to major allele negatives for both markers $(\mathrm{p}<0.001$ for $r \mathrm{~s} 11074932$ and $\mathrm{p}<0.0003$ for rs3087456) while no such difference is seen among DR15 positive individuals. This supports our conclusion that the CIITA association seem to be among DR15 negative individuals.

Since the association to T1D remained for two SNP markers (rs11074932 and rs3087456) even after controlling for age, gender and HLA, we suggest that these polymorphisms or other polymorphisms in close proximity are related to T1D susceptibility.

\section{$\underline{\text { Discussion }}$}

Given the pivotal role of CIITA for regulation of MHC class II gene transcription ${ }^{6}$, it is an obvious candidate for affecting susceptibility to autoimmune diseases known to be associated 
to MHC class II haplotypes ${ }^{22}$. Previous studies have reported positive ${ }^{19,20}$ but also negative ${ }^{23,24}$ results regarding association of CIITA to different autoimmune diseases.

In this study, we have performed LD mapping of the CIITA gene followed by an analysis of association to T1D. We identified a region extending between the PI and PIII promoters of the CIITA gene, which is modestly associated to T1D. This association remains significant after correcting for age, gender, HLA association and association to the neighboring CLEC16A gene, which is a nearby established T1D risk gene ${ }^{21}$. In a genome-wide association (GWA) scan performed by The Wellcome Trust Case Control Consortium (WTCCC) ${ }^{17}$ the $16 \mathrm{p} 13$ area was found to be significant associated to T1D. The CLEC16A gene has been thoroughly evaluated and found to be the major associated T1D risk gene in the area, and independent of the CIITA gene ${ }^{25}$. However this doesn't rule out the possibility that CIITA can have a minor role as well at a more modest level. In the mentioned investigation of the area there were inconclusive results regarding the association of CIITA, when significant association to T1D was found in a family material but not in the casecontrol cohort ${ }^{25}$. Our findings regarding the association of the CIITA gene to T1D is not genome wide significant, but in the complex settings of the T1D many genes with moderate influence are believed to have an impact on the etiology of the disease. This association between CIITA and T1D does however need to be confirmed in other materials to remain of interest.

We have in our study observed a significant difference in the genotype distribution for CIITA SNPs in a control cohort across different age groups, which we also confirm in an independent material of approximately 2000 individuals. The change in genotype frequency with age among controls in this gene can be one reason for the conflicting results of previously published CIITA case-control association studies. Thus, if one genotype or allele is 
less abundant among older control individuals, it could give a false association result for that genotype when compared with a younger patient group.

Possibly, this phenomenon may be relevant also for other genomic regions, and therefore suggest that proper matching of cases and controls with respect to age are important in genetic studies. This effect may not be evident when only analyzing an age restricted sample material. For example, no age effect was found among the T1D patients. However, with most of the T1D patients having an onset before the age of 30, they cover only part of the age span included in the investigation. The variation for rs4774 with age was not discovered in our initial combined control material, where only 18 individuals over the age of 75 were genotyped for this marker, but seen in the cohort study including about 100075 year old individuals. Possibly the effect for this marker is more profound for the oldest age groups, and the same tendency is seen for the rs3087456 marker, where the significance level improves when adding additional 75 year- or older individuals to the analysis. Although the discrepancies in results between association studies of the CIITA gene in part can be due to lack of statistical power to detect a small effect size, variability in outcome could also be affected by differences in age between patients and controls, a variable which often is not accounted for in genetic case-control studies.

There can be different underlying reason for an age effect on allele frequencies among the controls, which we will address in this discussion.

One reason could be population stratification, where the genotype frequencies vary among different population cohorts. Detailed data on ethnic origin was not available for all the cohorts included in this investigation, but when available, individuals with non-Scandinavian origin have been removed. The rs11074932 SNP is the marker varying most across the different age groups, with the $T T$ genotype increasing with age at the expense of the other genotypes. The minor allele in the European and African populations $(C)$ is the major allele 
in Japanese and Chinese populations. The distribution is similar for marker rs3087456, where the minor allele $(G)$ in Europeans is the major allele in Japanese and African populations, but not much information about population diversity regarding genotypes for these two markers is available. Theoretically infiltration of these populations could affect our findings.

However, since the controls used in this study were all collected from Swedish residents and individuals with non-Scandinavian descent were removed, no or very few Japanese/Chinese or African individuals have to our knowledge been included. Also, one could argue that these are only minor immigrant groups in Sweden, and their participation in study cohorts like the one described here are likely to be small. Hence, the variation we see in our material is unlikely to depend solely on population heterogeneity.

A maybe more reasonable and interesting theory concerns how the genotype affects health. It does not have to be a dramatic effect on longevity or survival, a small influence on the severity or recurrence of a common cold could be enough. If a certain genotype is associated with being healthier it might be more likely that these individuals are included as healthy controls for a medical study. Such an effect may be more pronounced for older individuals and will result in a skewing of genotypes in the study cohorts. Blood-donors are generally regarded as healthier than the general population. When we investigated the blood-donor control group from the MS cohort $1(n=1217)$, we found that they have a lower minor allele frequency for rs3087456 (0.22) than the combined control material together (0.24). Similarly, the minor allele frequency for rs 11074932 was 0.27 among blood donors compared to 0.28 in the whole material, regardless of age. This correlates with the findings that the older age groups in this study had a lower frequency of the minor allele homozygote genotype than did the younger groups.

The minor allele of rs3087456 has been associated with lower expression of MHC class II chains after stimulation of leukocytes with interferon- $\gamma^{15}$. Possibly, a higher frequency of the 
minor allele for these markers leads to less expression of the CIITA gene and subsequently less MHCII molecules, which in turn could lead to less effective antigen presentation and immune defense. If this also leads to more severe or more occurrence of infections, it will affect the possibility for those individuals to become a blood-donor or participate in a clinical study as a healthy control, maybe even more so if you are older. Theoretically, healthy older individuals in this study and blood donors are then expected to have increased expression of CIITA and therefore likely a more efficient clearance of infections.

A perhaps less likely explanation is that an infection or other environmental influence cause selection pressure for a certain genotype in the whole population, affecting the individual chance of survival. For this to occur, the infection in question must have conferred a high rate of mortality in young individuals, a scenario similar to what occurred due the Spanish flu epidemic.

Another reason for the variation of genotypes could be events that affect genotyping results. Since the genotyping of the different cohorts in this study has been performed with different methods we had in some cases overlapping results for the same individuals from different genotyping platforms (RA cohort, DASH and Taqman technology). We could not find any major discrepancy in genotyping results in this test sample (one mismatch out of 664 samples). Also, the RA cohort was re-genotyped with Taqman technology with a $100 \%$ concordance in results. It could be considered advantageous that different methods have been used, since it minimizes the effect of an introduced systematic error. All genotyping platforms used are well established and described.

Whatever the cause is, it is important to consider the effect it has on association studies and thoroughly choose well-matched controls in these cases. This variance could clearly affect the results of an association study that doesn't consider the age among the control group compared to the patient cohort. 
The association found to T1D in this study is of moderate strength and not genome wide significant. However the importance of the CIITA gene's function in the immune system makes it plausible that it can have an effect on the pathogenesis of T1D. The two markers (rs3087456 and rs11074932) investigated here are in quite high linkage disequilibrium, 76\% $\left(r^{2}\right)$, with each other (fig4), and for both markers it is the major allele homozygote that is associated to T1D. Since there are earlier findings of lower expression of MHC class II chains after stimulation of leukocytes with interferon- $\gamma^{15}$ for the minor allele of rs3087456, it is possible that a lower expression of CIITA and subsequently MHCII molecules could be protective to T1D in the way of less efficient self-antigen presentation, and higher or "normal" levels of CIITA correlating to the major allele genotype are involved in susceptibility. This correlates with our theory regarding the health aspect described above. Further functional studies are needed to investigate how different alleles may affect the expression of MHC class II in the setting of T1D.

In summary, we report an age dependent variation in SNPs located in the CIITA gene among control materials. In addition, we demonstrate a significant, albeit modest association to T1D for SNPs located in the genomic region of the PI and PIII promoters of the CIITA gene after controlling for age. Taken together these results suggest that replication of this association and other association studies in case-control materials should be performed with careful matching for age.

\section{Materials and Methods}

\section{Ethics Statement}

All included cohorts, patient material and analyses in this study were approved by the Regional Ethical Review Boards in the citites of Stockholm, Lund and Umeå in Sweden 
(www.epn.se). Informed consent from all study participants or their parents was obtained. Investigations were carried out according to guidelines from the Declaration of Helsinki.

\section{Subjects: Type 1 diabetes patients and controls}

\section{$\underline{\text { Diabetes Incidence Study in Sweden } 1 \text { (DISS1) }}$}

The DISS1 cohort consists of DNA samples from 839 T1D patients and 625 sex, age and residence matched controls. Blood was collected from incidence patients from the Diabetes Incidence Study in Sweden (DISS) registry, diagnosed between 1987 and 1989, at the age of 15-36 years ${ }^{26} .667$ of the patients were classified with T1D by the treating physician.

Sufficient DNA was available for 431 T1D cases and 348 controls in this cohort, these were the individuals included in the current investigation.

\section{Diabetes Incidence Study in Sweden 2 (DISS2)}

The DISS2 cohort consists of DNA samples from 778 incident diabetes patients aged 15-36 years and from the DISS registry during 1992 and 1993, and 836 sex and age- matched controls ${ }^{16} .586$ of the patients were classified with T1D at follow-up and these subjects are included in this study.

\section{$\underline{\text { Swedish Childhood Study (Sv2) }}$}

497 cases of children between 0-14 years with newly diagnosed T1D collected from the Swedish Childhood registry. Controls were geographically, gender and age matched to all cases above 7 years of age $(n=423)$. For patients under the age of 7 years a control was selected among patients being treated at the hospital for reasons other than T1D $(n=53)^{27}$. $\underline{\text { Better Diabetes Diagnosis Study (BDD) }}$

2700 incident diabetes patients under the age of 18 years at diagnosis, collected between 2005 and 2009 from 40 pediatric clinics in Sweden for the Better Diabetes Diagnosis study ${ }^{28}$. 
Only patients diagnosed with T1D and with all parents and grandparents born in Scandinavia are included in this study.

\section{Diabetes Registry in Southern Sweden (DR)}

804 T1D patients, 436 men and 368 women, with onset age between 1 and 75 years of age, from the Diabetes Registry in Southern Sweden, all enlisted at the Dep. of Endocrinology at Malmö University Hospital, Sweden and collected between 1996 and 2005. Additionally, 2312 healthy controls, 1695 men and 617 women between 45 and 75 years of age ${ }^{29}$. Individuals of known non-Scandinavian origin were excluded $(\mathrm{n}=100)$.

Due to risk for overlap among patients in the DISS2 and DR cohorts, those individuals that could possibly occur in both cohorts were identified and removed from this study $(n=73)$. To our knowledge there are no other cohorts in this study that could be overlapping.

\section{Extra control cohorts:}

\section{$\underline{\text { Rheumatoid arthritis (RA) }}$}

1426 healthy controls matched to RA patients by age, sex and residential area. The recruitment of affected individuals and controls was described previously in connection with EIRA study ${ }^{30} .373$ of these controls were used in the SNP tagging analysis.

Individuals deviating in a PCA analysis or of known non-Scandinavian origin were excluded from this study $(\mathrm{n}=93)^{31}$.

\section{$\underline{\text { Multiple sclerosis (MS) }}$}

From the Swedish MS 1 cohort, the control group consisted of 1215 healthy blood donors originating from Sweden or other Nordic countries ${ }^{32}$.

From the Swedish MS 2 cohort, we used 663 controls matched for age, sex, and residential location to newly diagnosed MS cases resident throughout Sweden in the EIMS studies ${ }^{33}$. 
All individuals of known non-Scandinavian origin were excluded from the current study $(n=190)$.

\section{Myocardial infarction - SCARF (MI)}

From the $\mathrm{SCARF}^{15}$ study the control group consists of 387 sex- and age-matched healthy persons between 40-60 years of age, and recruited from the general population of the same county as cases with MI, of self-reported Caucasian origin.

\section{$\underline{\text { Alzheimer's disease - SNAC (AD) }}$}

424 healthy controls of 60-73 years of age, from an earlier study of $\mathrm{AD}^{34}$, randomly selected and sex-matched from 3500 individuals included in the longitudinal study: The Swedish National Study on Aging and Care in Kungsholmen (SNACK), in Stockholm, Sweden. Also, originally added to this cohort are 39 individuals which are autopsy cases from the Karolinska Brainbank who died from cardiovascular or malignant diseases, between 56-91 years of age and without a medical history of dementia ${ }^{34}$.

\section{Population based control cohorts from Osteoporosis study (PEAK-25 and OPRA)}

The PEAK-25 cohort consists of 1005 healthy women of Swedish or Northeuropean ancestry. The women are all 25 years old and randomly selected from the Malmö city files between 1999 and $2003 .^{35}$

The second cohort consists of 1010 healthy controls from the Malmö Osteoporosis Prospective Risk Assessment (OPRA) study, all aged 75 years and of Swedish or Northeuropean ancestry, randomly selected from the Malmö city files between 1995 and $1999^{36}$

Additional information regarding the cohorts is available as a supplementary table (S3).

\section{Genotyping methods}


In the DISS2 cohort the allelic discrimination method for SNPs (single nucleotide polymorphisms) TaqMan ABI 7900 (Applied Biosystems, Inc ABI, Sweden) ${ }^{37}$ was used for all markers except for rs4774, rs3087456 and rs8052709 for which the DASH ${ }^{38}$ method was used.

SNP genotyping for DISS1 and SV-2 studies was performed using the MassArray chip-based matrix-assisted laser desorption/ionization time-of-flight mass spectrometer (Sequenom Inc., San Diego, CA, USA) using the HME chemistry as described ${ }^{39}$.

T1D samples and controls from Diabetes registry in Southern Sweden (DR) and the BDD cohort were genotyped with the TaqMan method.

In the gathered control material from RA, MS and MI, samples was genotyped as previously described ${ }^{15}$. Additional samples from these cohorts were genotyped with the TaqMan method. The controls from the AD cohort were genotyped with DASH.

In the PEAK-25 and OPRA cohorts, markers rs4774 and rs3087456 was genotyped with IPLEX (Sequenom Inc., San Diego, CA, USA) and rs11074932 was genotyped with Taqman.

\section{HLA typing}

HLA typing in the different cohorts were performed as follow;

DISS1 and SV2: restriction fragment-length polymorphism (RFLP) was used for DR typing, and genotyping for $D Q B 1, D Q A 1$ and $D R B 1$ was performed with PCR amplification followed by dot blot hybridizations ${ }^{13}$.

DISS2: HLA genotyping for $D Q B 1, D Q A 1$ and $D R B 1$ was performed with PCR amplification followed by dot blot hybridizations and by RFLP as previously described ${ }^{13}$, except that allele-specific PCR amplification (PCR-SSP) of DRB1 alleles was also used ${ }^{40}$ BDD: A method based on an asymmetrical PCR and a subsequent hybridization of allelespecific probes was used, as described previously ${ }^{41}$. Established haplotypes in the European 
population were used to determine DR genotypes in the BDD cohort where only DQAl and $D Q B 1$ were genotyped.

MS and RA: Genotyping by allele specific amplification as described earlier ${ }^{40}$.

The other cohorts had no data concerning HLA status.

\section{Tag SNPs and haplotype blocks}

41 SNP markers were selected from dbSNP (http://www.ncbi.nlm.nih.gov/SNP/) to be evenly spread across 66428 bp of the CIITA gene (before PI to 3' UTR). Previously validated SNPs were chosen preferentially. The average marker spacing was 1468 bp (range $86-4030$ bp). All SNPs were first genotyped in a selected cohort of 373 controls. 13 of the selected SNPs were non-polymorphic and one did not follow Hardy-Weinberg equilibrium and were discarded from further studies $(S 1)$.

Genotypes from the remaining 28 SNPs were used to analyze linkage disequilibrium (LD) block structure and to identify haplotype tagging SNPs (htSNPs). The results from this analysis revealed five LD blocks (S2), and common haplotypes in each block could be resolved by typing 1 to 3 htSNPs. LD blocks and htSNPs were accomplished using the HapBlock analysis program ${ }^{42-44}$. The block partitioning algorithm was set as the dynamic programming algorithm, ${ }^{42}$ the common haplotype method was used for block partitioning and the method for identifying htSNPs was capable of identifying all common (> 5\%) haplotypes.

\section{Age stratification}

Controls from studies of RA, MS, AD and MI together with T1D controls (DISS1, DISS2, SV2, DR) were analysed for three SNP markers, rs11074932 (C/T) 3747 controls, rs3087456 $(A / G) 7331$ controls and rs4774 (C/G) 3317 controls (S3). 
The controls were divided into fifteen 5 years intervals with respect to age at sampling $(0-4$, 5-9 .... 65-69, and >70).

\section{Statistical analysis}

Pearson's Chi-squared test was used to detect overall association, logistic regression analysis using generalized linear modeling between the persons with diabetes and the general population, was used to correct for the effect of age and HLA on the CIITA association. When correcting for age in logistic regression, the age-group 7 (30-35 years) was used as a reference group. In the logistic regression model where HLA was included as a factor, only individuals with data regarding $D R B 1 * 04$ haplotype were included in these analyses to be able to compare results, since this was a limiting factor. HLA coding was otherwise defined as presence or absence of allele for $D R B 1 * 15$ and $D R B 1 * 03$, for $D R B 1 * 04$, only individuals with $D R B 1 * 04 * D Q B 1-03: 02$ were considered positive for $D R B 1 * 04$.

Chi-squared Test for Trend in Proportions was used to detect the overall trend in variation of genotype over age. Pearson's Chi-squared test was also used to detect differences in genotype and allele frequencies between the two age groups in the population based cohorts used for replication.

A joint age-stratified ("meta-analysis over age-groups") test of association in CIITA with T1D in the combined cohort of five case-control studies was performed for the first 8 agegroups, (0-39 years) using fixed effect Mantel-Haenszel analysis and Woolf's test for heterogeneity in $\mathrm{R}$ using the meta.MH command in the rmeta package. In rs3087456_GG, age group 1 (0-4 yrs) was removed from the analysis due to heterogeneity between groups $(\mathrm{p}=0.04)$

To investigate interaction between the CIITA gene and HLA haplotypes, departure from additivity was estimated by calculating attributable proportion (AP) due to interaction. These 
analyses were performed as described ${ }^{45}$, using the generalized linear modeling (glm) in $\mathrm{R}$ and the vcov command to get the covariance matrix. As suggested by Knol et al, the group with the lowest OR when both factors are considered jointly have been used as reference group when calculating $\mathrm{AP}^{46}$, however the OR plotted in fig. 5 are from the analysis when DR15 and CIITA minor allele positives were used as a reference group to clarify the interaction effect. The modeling included the SNP marker of investigation, as well as HLA haplotypes and age groups described as above.

All statistical analyses were performed in the statistical computer program $\mathrm{R}$ version $2.6 .2^{47}$, except the initial association analysis which was performed in Unphased $^{48}$ using the cocaphase command. An LD plot over the markers in the DISS2 cohort was performed in Haploview $4.2(\text { fig } 4)^{49}$.

Supplementary information is available at Genes\&Immunity’s website.

\section{$\underline{\text { Acknowledgments }}$}

We thank Jana L. Hoehna and Marta Janer for their contribution to this work.

We acknowledge Professor Laura Fratiglioni and co-workers in the SNACK-project for the SNACK controls and Dr Behnosh F Björk for the sample handling.

This work was supported by grants from the Juvenile Diabetes Research Foundation International (2-2000-570) and (1-2001-873), the Swedish Research Council, Swedish Diabetes Foundation (Svenska Diabetes Fonden), Swedish Child Diabetes Foundation (Barndiabetes Fonden), Novo Nordisk Foundation, Magnus Bergvalls Foundation and Neuropromise (LSHM-CT-2005-018637). The Molecular and Genetics Core of the Diabetes Endocrinology Research Center is supported by NIH grant DK-17047.

The project was also supported by the Swedish Brain Power initiative, Gun and Bertil Stohne’s Foundation, Foundation for Old Servants, Alzheimer Foundation and LIONS 
Foundation for Research of Age Related Disorders, the AFA foundation, the Söderberg Foundation, Knut and Alice Wallenbergs Foundation.

The funders had no role in study design, data collection and analysis, decision to publish, or preparation of the manuscript.

\section{$\underline{\text { Conflict of interest }}$}

The authors declare no financial, personal or professional conflict of interest. 


\section{$\underline{\text { References }}$}

1. Todd JA. Genetic analysis of type 1 diabetes using whole genome approaches. Proc Natl Acad Sci U S A 1995; 92(19): 8560-5.

2. Kockum I, Sanjeevi CB, Eastman S, Landin-Olsson M, Dahlquist G, Lernmark A. Complex interaction between HLA DR and DQ in conferring risk for childhood type 1 diabetes. Eur J Immunogenet 1999; 26(5): 361-72.

3. Graham J, Kockum I, Sanjeevi CB, Landin-Olsson M, Nystrom L, Sundkvist G et al. Negative association between type 1 diabetes and HLA DQB1*0602-DQA1*0102 is attenuated with age at onset. Swedish Childhood Diabetes Study Group. Eur J Immunogenet 1999; 26(2-3): 117-27.

4. Masternak K, Muhlethaler-Mottet A, Villard J, Zufferey M, Steimle V, Reith W. CIITA is a transcriptional coactivator that is recruited to MHC class II promoters by multiple synergistic interactions with an enhanceosome complex. Genes Dev 2000; 14(9): 1156-66.

5. Zhou H, Glimcher LH. Human MHC class II gene transcription directed by the carboxyl terminus of CIITA, one of the defective genes in type II MHC combined immune deficiency. Immunity 1995; 2(5): 545-53.

6. Steimle V, Siegrist CA, Mottet A, Lisowska-Grospierre B, Mach B. Regulation of MHC class II expression by interferon-gamma mediated by the transactivator gene CIITA. Science 1994; 265(5168): 106-9. 
7. Klein C, Lisowska-Grospierre B, LeDeist F, Fischer A, Griscelli C. Major histocompatibility complex class II deficiency: clinical manifestations, immunologic features, and outcome. J Pediatr 1993; 123(6): 921-8.

8. Muhlethaler-Mottet A, Otten LA, Steimle V, Mach B. Expression of MHC class II molecules in different cellular and functional compartments is controlled by differential usage of multiple promoters of the transactivator CIITA. EMBO J 1997; 16(10): 2851-60.

9. LeibundGut-Landmann S, Waldburger JM, Reis e Sousa C, Acha-Orbea H, Reith W. MHC class II expression is differentially regulated in plasmacytoid and conventional dendritic cells. Nat Immunol 2004; 5(9): 899-908.

10. Sartoris S, Brendolan A, Degola A, Testi MG, Chignola R, Scarpa A et al. Analysis of CIITA encoding AIR-1 gene promoters in insulin-dependent diabetes mellitus and rheumatoid arthritis patients from the northeast of Italy: absence of sequence variability. Hum Immunol 2000; 61(6): 599-604.

11. Nerup J, Pociot F. A genomewide scan for type 1-diabetes susceptibility in Scandinavian families: identification of new loci with evidence of interactions. Am J Hum Genet 2001; 69(6): 1301-13.

12. Caillat-Zucman S, Garchon HJ, Timsit J, Assan R, Boitard C, Djilali-Saiah I et al. Age-dependent HLA genetic heterogeneity of type 1 insulin-dependent diabetes mellitus. J Clin Invest 1992; 90(6): 2242-50.

13. Graham J, Hagopian WA, Kockum I, Li LS, Sanjeevi CB, Lowe RM et al. Genetic effects on age-dependent onset and islet cell autoantibody markers in type 1 diabetes. Diabetes 2002; 51(5): 1346-55. 
14. Trynka G, Hunt KA, Bockett NA, Romanos J, Mistry V, Szperl A et al. Dense genotyping identifies and localizes multiple common and rare variant association signals in celiac disease. Nat Genet 2011; 43(12): 1193-201.

15. Swanberg M, Lidman O, Padyukov L, Eriksson P, Akesson E, Jagodic M et al. MHC2TA is associated with differential MHC molecule expression and susceptibility to rheumatoid arthritis, multiple sclerosis and myocardial infarction. Nat Genet 2005; 37(5): 486-94.

16. Jensen RA, Gilliam LK, Torn C, Landin-Olsson M, Karlsson FA, Palmer JP et al. Multiple factors affect the loss of measurable C-peptide over 6 years in newly diagnosed 15- to 35-year-old diabetic subjects. J Diabetes Complications 2007; 21(4): 205-13.

17. Consortium WTCC. Genome-wide association study of 14,000 cases of seven common diseases and 3,000 shared controls. Nature 2007; 447(7145): 661-78.

18. Bronson PG, Caillier S, Ramsay PP, McCauley JL, Zuvich RL, De Jager PL et al. CIITA variation in the presence of HLA-DRB $1 * 1501$ increases risk for multiple sclerosis. Hum Mol Genet 2010; 19(11): 2331-40.

19. Iikuni N, Ikari K, Momohara S, Tomatsu T, Hara M, Yamanaka H et al. MHC2TA is associated with rheumatoid arthritis in Japanese patients. Ann Rheum Dis 2007; 66(2): 274-5. 
20. Martinez A, Sanchez-Lopez M, Varade J, Mas A, Martin MC, de Las Heras V et al. Role of the MHC2TA gene in autoimmune diseases. Ann Rheum Dis 2007; 66(3): 325-9.

21. Cooper JD, Walker NM, Smyth DJ, Downes K, Healy BC, Todd JA. Follow-up of 1715 SNPs from the Wellcome Trust Case Control Consortium genome-wide association study in type I diabetes families. Genes Immun 2009; 10 Suppl 1: S85-94.

22. Larsen CE, Alper CA. The genetics of HLA-associated disease. Curr Opin Immunol 2004; 16(5): 660-7.

23. Eyre S, Bowes J, Spreckley K, Potter C, Ring S, Strachan D et al. Investigation of the MHC2TA gene, associated with rheumatoid arthritis in a Swedish population, in a UK rheumatoid arthritis cohort. Arthritis Rheum 2006; 54(11): 3417-22.

24. Harrison P, Pointon JJ, Farrar C, Harin A, Wordsworth BP. MHC2TA promoter polymorphism $\left(-168^{*} \mathrm{G} / \mathrm{A}, \mathrm{rs} 3087456\right)$ is not associated with susceptibility to rheumatoid arthritis in British Caucasian rheumatoid arthritis patients. Rheumatology (Oxford) 2007; 46(3): 409-11.

25. Todd JA, Walker NM, Cooper JD, Smyth DJ, Downes K, Plagnol V et al. Robust associations of four new chromosome regions from genome-wide analyses of type 1 diabetes. Nat Genet 2007; 39(7): 857-64.

26. Landin-Olsson M, Karlsson FA, Lernmark A, Sundkvist G. Islet cell and thyrogastric antibodies in 633 consecutive 15- to 34 -yr-old patients in the diabetes incidence study in Sweden. Diabetes 1992; 41(8): 1022-7. 
27. Dahlquist G, Blom L, Tuvemo T, Nystrom L, Sandstrom A, Wall S. The Swedish childhood diabetes study--results from a nine year case register and a one year casereferent study indicating that type 1 (insulin-dependent) diabetes mellitus is associated with both type 2 (non-insulin-dependent) diabetes mellitus and autoimmune disorders. Diabetologia 1989; 32(1): 2-6.

28. Carlsson A, Kockum I, Lindblad B, Engleson L, Nilsson A, Forsander G et al. Low risk HLA-DQ and increased body mass index in newly diagnosed type 1 diabetes children in the Better Diabetes Diagnosis study in Sweden. In: Int J Obes (Lond). 2011/06/30 ed, 2011.

29. Lindholm E, Agardh E, Tuomi T, Groop L, Agardh CD. Classifying diabetes according to the new WHO clinical stages. Eur J Epidemiol 2001; 17(11): 983-9.

30. Stolt P, Bengtsson C, Nordmark B, Lindblad S, Lundberg I, Klareskog L et al. Quantification of the influence of cigarette smoking on rheumatoid arthritis: results from a population based case-control study, using incident cases. Ann Rheum Dis 2003; 62(9): 835-41.

31. Plenge RM, Seielstad M, Padyukov L, Lee AT, Remmers EF, Ding B et al. TRAF1C5 as a risk locus for rheumatoid arthritis--a genomewide study. $N$ Engl J Med 2007; 357(12): 1199-209.

32. Roos IM, Kockum I, Hillert J. The interleukin 23 receptor gene in multiple sclerosis: a case-control study. J Neuroimmunol 2008; 194(1-2): 173-80. 
33. Hedstrom AK, Baarnhielm M, Olsson T, Alfredsson L. Tobacco smoking, but not Swedish snuff use, increases the risk of multiple sclerosis. Neurology 2009; 73(9): 696-701.

34. Bjork BF, Katzov H, Kehoe P, Fratiglioni L, Winblad B, Prince JA et al. Positive association between risk for late-onset Alzheimer disease and genetic variation in IDE. Neurobiol Aging 2007; 28(9): 1374-80.

35. McGuigan FE, Larzenius E, Callreus M, Gerdhem P, Luthman H, Akesson K. Variation in the BMP2 gene: bone mineral density and ultrasound in young adult and elderly women. Calcif Tissue Int 2007; 81(4): 254-62.

36. Gerdhem P, Isaksson A, Akesson K, Obrant KJ. Increased bone density and decreased bone turnover, but no evident alteration of fracture susceptibility in elderly women with diabetes mellitus. Osteoporos Int 2005; 16(12): 1506-12.

37. Ekelund E, Saaf A, Tengvall-Linder M, Melen E, Link J, Barker J et al. Elevated expression and genetic association links the SOCS3 gene to atopic dermatitis. Am J Hum Genet 2006; 78(6): 1060-5.

38. Prince JA, Feuk L, Howell WM, Jobs M, Emahazion T, Blennow K et al. Robust and accurate single nucleotide polymorphism genotyping by dynamic allele-specific hybridization (DASH): design criteria and assay validation. Genome Res 2001; 11(1): 152-62.

39. Roach JC, Deutsch K, Li S, Siegel AF, Bekris LM, Einhaus DC et al. Genetic mapping at 3-kilobase resolution reveals inositol 1,4,5-triphosphate receptor 3 as a risk factor for type 1 diabetes in sweden. Am J Hum Genet 2006; 79(4): 614-27. 
40. Olerup O, Zetterquist H. HLA-DR typing by PCR amplification with sequencespecific primers (PCR-SSP) in 2 hours: an alternative to serological DR typing in clinical practice including donor-recipient matching in cadaveric transplantation. Tissue Antigens 1992; 39(5): 225-35.

41. Kiviniemi M, Hermann R, Nurmi J, Ziegler AG, Knip M, Simell O et al. A highthroughput population screening system for the estimation of genetic risk for type 1 diabetes: an application for the TEDDY (the Environmental Determinants of Diabetes in the Young) study. Diabetes Technol Ther 2007; 9(5): 460-72.

42. Zhang K, Deng M, Chen T, Waterman MS, Sun F. A dynamic programming algorithm for haplotype block partitioning. Proc Natl Acad Sci U S A 2002; 99(11): 7335-9.

43. Zhang K, Jin L. HaploBlockFinder: haplotype block analyses. Bioinformatics 2003; 19(10): 1300-1.

44. Zhang K, Qin ZS, Liu JS, Chen T, Waterman MS, Sun F. Haplotype block partitioning and tag SNP selection using genotype data and their applications to association studies. Genome Res 2004; 14(5): 908-16.

45. Andersson T, Alfredsson L, Kallberg H, Zdravkovic S, Ahlbom A. Calculating measures of biological interaction. Eur J Epidemiol 2005; 20(7): 575-9. 
46. Knol MJ, VanderWeele TJ. Recoding preventive exposures to get valid measures of interaction on an additive scale. Eur J Epidemiol 2011; 26(10): 825-6; author reply 826.

47. R Development Core Team. R: A language and environment for statistical computing. In. Vienna, Austria: R Foundation for Statistical Computing,, 2008.

48. Dudbridge F. Likelihood-based association analysis for nuclear families and unrelated subjects with missing genotype data. Hum Hered 2008; 66(2): 87-98.

49. Barrett JC, Fry B, Maller J, Daly MJ. Haploview: analysis and visualization of LD and haplotype maps. Bioinformatics 2005; 21(2): 263-5. 


\section{Figure Legends}

Figure 1. Genotype distribution with age in CIITA among controls.

Genotype frequencies in percent for A) rs11074932 B) rs3087456 and C) rs4774 related to age-group (number of individuals in parenthesis). P-value for respectively genotype in test for trend-over-age. For B) the p-value for the AA genotype is 0.09 if the oldest group (over75 yrs of age) is removed.

\section{Figure 2. Genotype frequencies in cohort material.}

Genotype frequencies in marker rs11074932, rs3087456 and rs4774 in the two groups of the cohort material ( 25 years old, $\mathrm{n}=1005$ and 75 years old, $\mathrm{n}=1010$ individuals).

P-values for genotypes in $2 \times 3$ chi-sqr test.

Figure 3. Age-stratified analysis of association in CIITA with type 1 diabetes.

Association in the combined cohort of five Scandinavian case-control studies for individuals under 40 years of age, of rs11074932 and rs3087456 in CIITA with Type 1 diabetes.

Meta analysis of age-groups with 5 years intervals and using the frequency of the genotypes for each marker.

Figure 4. Linkage disequlibrium plot of CIITA and CLEC16A in the DISS2 cohort. Linkage disequilibrium of the CIITA to CLEC16A gene region in the DISS2 cohort; darker gray indicates higher $\mathrm{r}^{2}$ between markers. (Haploview 4.2)

Figure 5. Interaction between $D R B 1 * 15$ and markers in CIITA.

Lack of $D R B 1 * 15$ together with the major allele homozygote increases the OR for type 1 diabetes. Error bars are 95\% CI of OR estimates. 
Attributable proportion (AP) is the proportion of the incidence among individuals exposed to both associated factors compared to the factors individually. The AP value is significant if separate from zero.

HLA is coded as absence of HLA allele for DRB $1 * 15$. The CIITA SNPS were coded as absence of minor allele for both markers.

\section{$\underline{\text { Supplementary material }}$}

S1. SNP positions and association analysis for T1D in the DISS2 cohort.

S2. LD block analysis in 373 Caucasian controls

S3. Cohorts - numerical summary

S4. Members of the Swedish Childhood Diabetes Study Group, the Diabetes Incidence in Sweden Study Group and the Better Diabetes Diagnosis Study group. 
$\underline{\text { Tables }}$

Table 1 Allele frequency and p-values for OPRA and PEAK cohorts

\begin{tabular}{|c|c|c|c|c|c|}
\hline $\begin{array}{c}\text { Minor allele } \\
\text { frequency }\end{array}$ & $\begin{array}{c}\text { PEAK- } \\
25 \text { yrs old }\end{array}$ & $\begin{array}{c}\text { OPRA- } \\
75 \text { yrs old }\end{array}$ & p-value allele & $\begin{array}{c}\text { p-value } \\
\text { p-value } \\
\text { genotypes }\end{array}$ & $\begin{array}{c}{ }^{2} \\
\text { minor allele } \\
\text { homozygote } \\
\text { genotype }^{3}\end{array}$ \\
\hline rs11074932-C & 0.303 & 0.271 & 0.03 & 0.02 & 0.006 \\
\hline rs3087456-G & 0.270 & 0.235 & 0.01 & 0.01 & 0.007 \\
\hline rs4774-C & 0.301 & 0.311 & 0.52 & 0.64 & 0.03 \\
\hline
\end{tabular}

${ }^{1} 2 \times 2$ Chi Sqr test for variation between groups in allele distribution ${ }^{2} 2 \times 3$ Chi Sqr test for variation between groups in genotype frequency

${ }^{3} 2 \times 2$ Chi Sqr test for variation between groups in minor allele homozygotes vs. other genotypes frequency 
Table 2 Association of CIITA to Type 1 Diabetes in the combined T1D cases and controls.

\begin{tabular}{|c|c|c|c|c|c|c|}
\hline Marker & $\begin{array}{l}\text { cases \% } \\
(\mathrm{n})\end{array}$ & $\begin{array}{l}\text { controls\% } \\
\text { (n) }\end{array}$ & $\begin{array}{c}\text { chi }^{1} \\
\text { (p-value) }\end{array}$ & $\begin{array}{l}\log \text { reg }^{2} \\
\text { (p-value) }\end{array}$ & $\begin{array}{c}\text { logreg corrected for age }{ }^{3} \\
(P \text {-value })\end{array}$ & $\begin{array}{c}\text { logreg } \\
\text { minor } \\
\text { allele } \\
\text { corrected } \\
\text { for age } \\
\text { (P-value) }\end{array}$ \\
\hline \multicolumn{7}{|c|}{ rs11074932 } \\
\hline TT & $53 \%(1374)$ & $48 \%(595)$ & & & & \\
\hline $\mathrm{CT}$ & $39 \%(1012)$ & $43 \%(533)$ & & 0.007 & 0.006 & \\
\hline $\mathrm{CC}$ & $8 \%(195)$ & $9 \%(115)$ & & 0.15 & 0.15 & \\
\hline Total $n$ & 2581 & 1243 & 0.005 & & & 0.004 \\
\hline \multicolumn{7}{|c|}{ rs3087456 } \\
\hline$\overline{A A}$ & $59 \%(1945)$ & $55 \%(1981)$ & & & & \\
\hline$A G$ & $35 \%(1139)$ & $38 \%(1369)$ & & 0.001 & 0.003 & \\
\hline$G G$ & $6 \%(200)$ & $7 \%(251)$ & & 0.040 & 0.09 & \\
\hline Total $\mathrm{n}$ & 3284 & 3601 & 0.002 & & & 0.001 \\
\hline \multicolumn{7}{|l|}{ rs4774 } \\
\hline$G G$ & $48 \%(605)$ & $47 \%(616)$ & & & & \\
\hline GC & $42 \%(528)$ & $43 \%(563)$ & & 0.58 & 0.58 & \\
\hline CC & $10 \%(126)$ & $10 \%(131)$ & & 0.88 & 0.96 & \\
\hline Total $n$ & 1259 & 1310 & 0.86 & & & 0.62 \\
\hline
\end{tabular}

${ }^{1} 2 \times 3$ Chi Sqr test for association of genotypes to T1D without correction for age at sampling

${ }^{2}$ Logistic regression analysis testing association of heterozygotes and minor allele homozygotes with major allele homozygotes as reference group

${ }^{3}$ Logistic regression analysis testing association of heterozygotes and minor allele homozygotes with major allele homozygotes as reference group, age at sampling was included as covariates.

${ }^{4}$ Logistic regression analysis testing association of presence of minor allele with major allele homozygotes as reference group, age at sampling was included as covariates. 
Fig 1

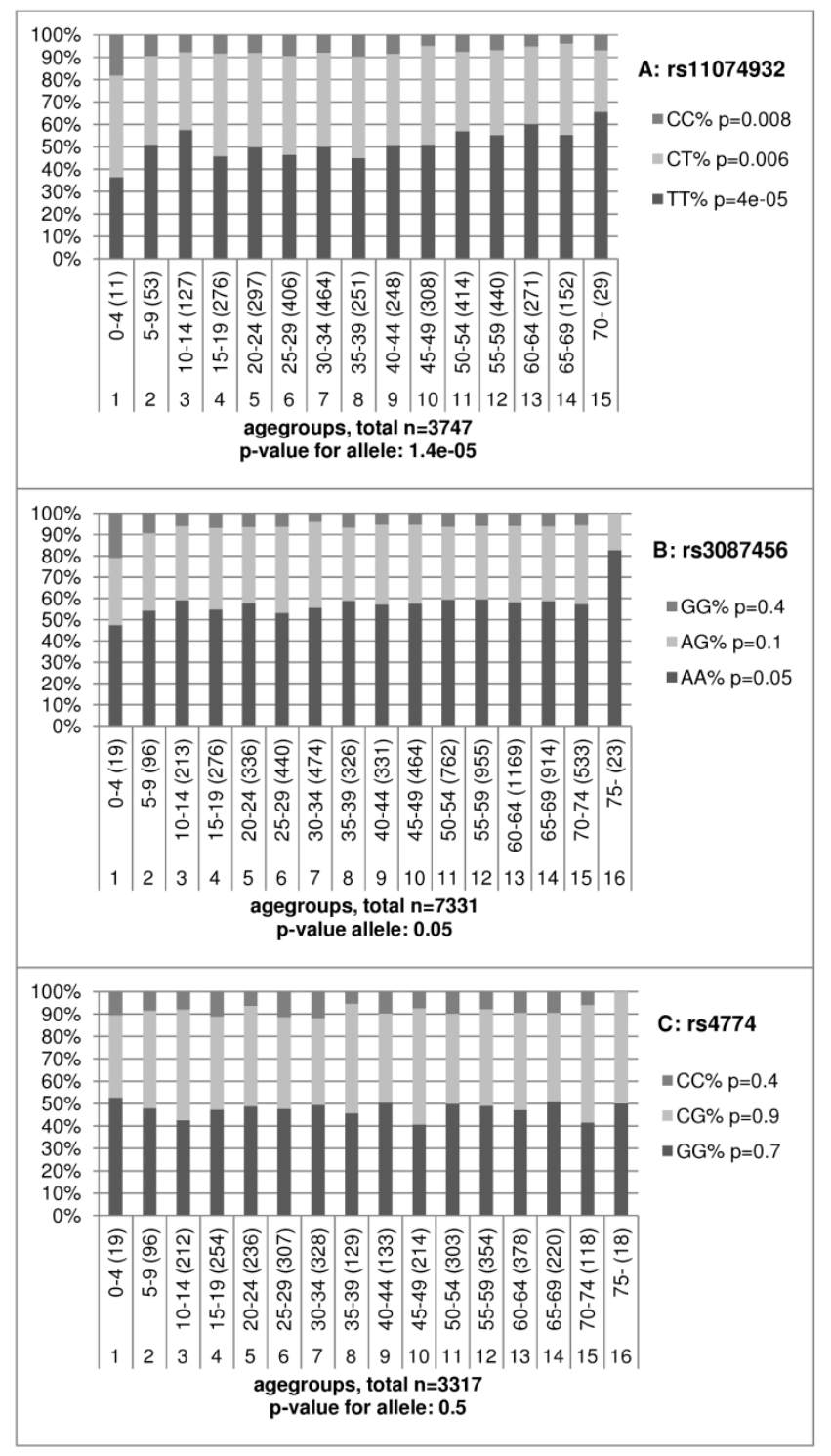

Fig 2

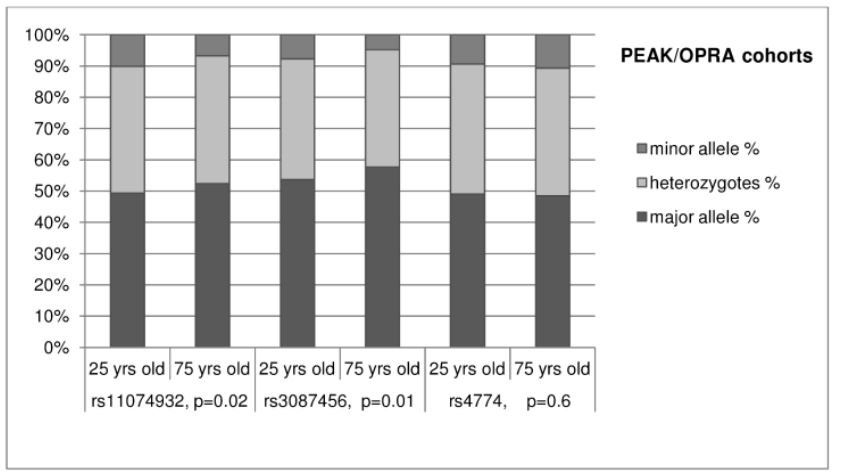


Fig 3
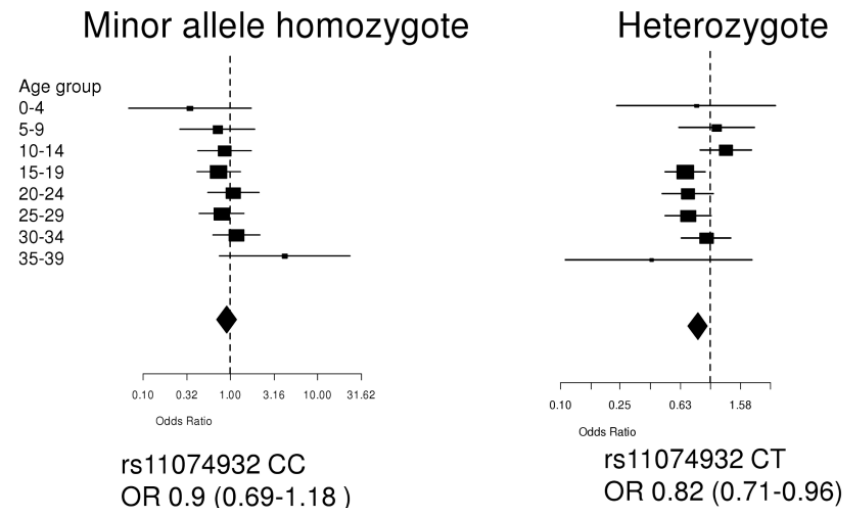

Major allele homozygote
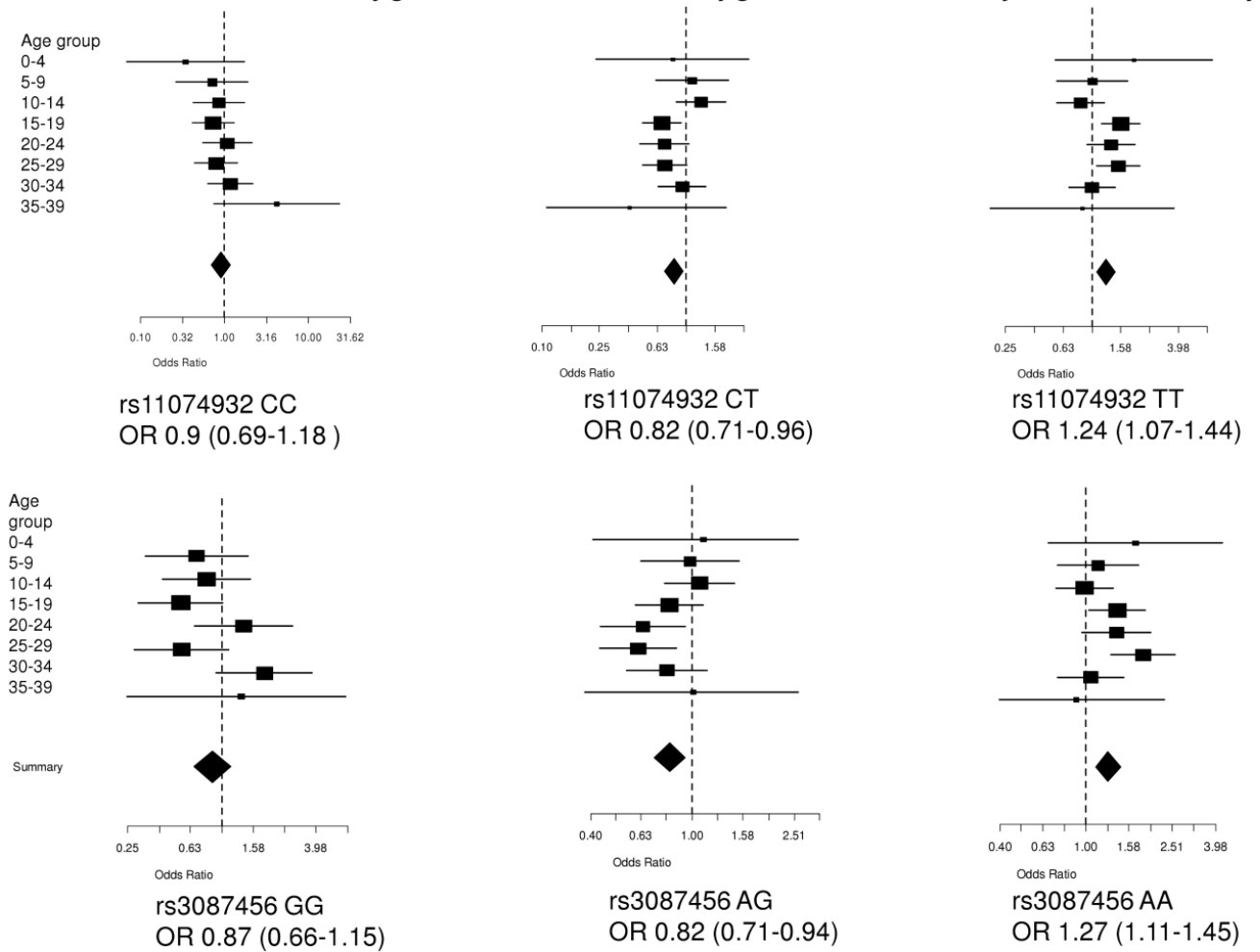
Fig 4

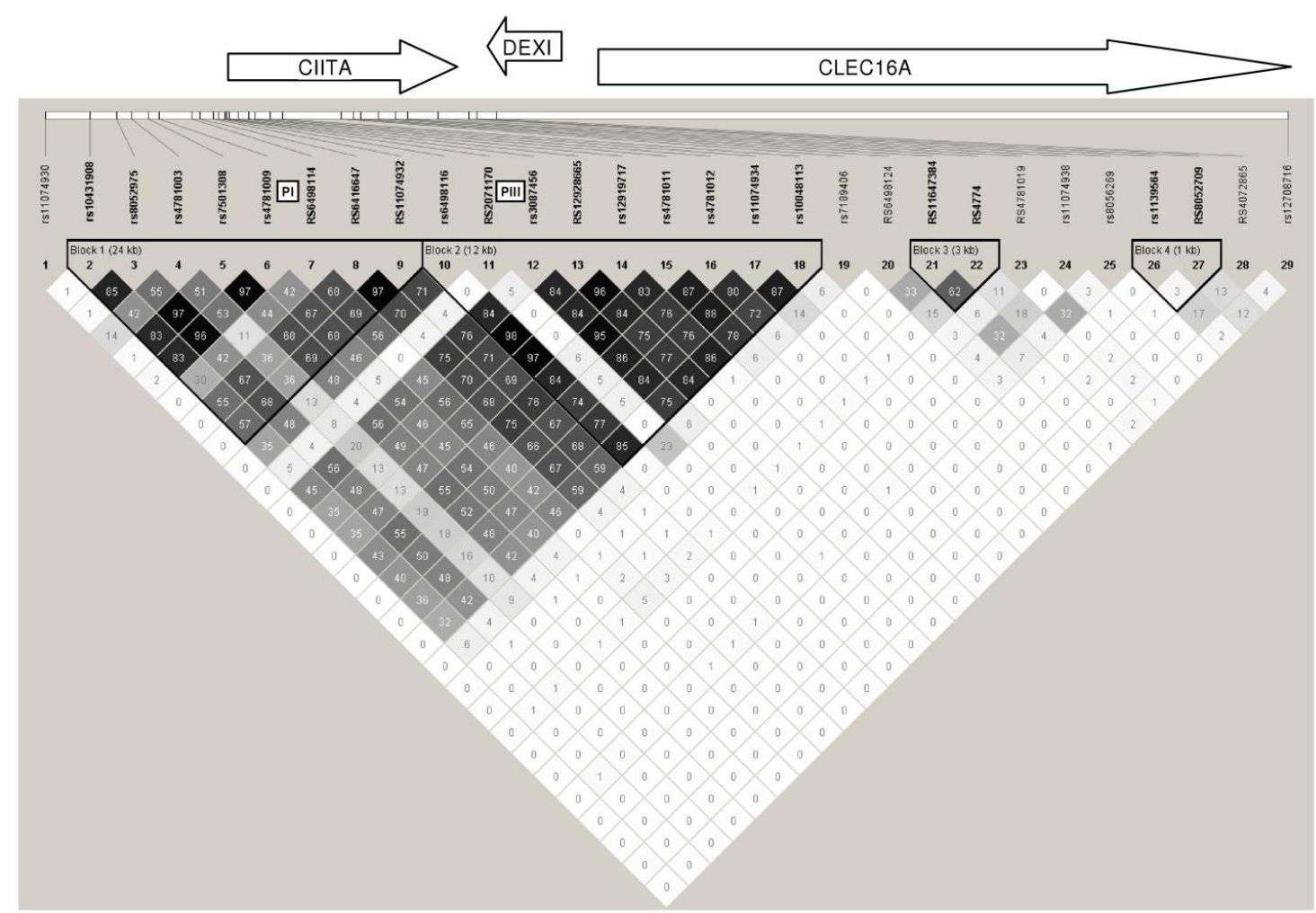


Fig 5
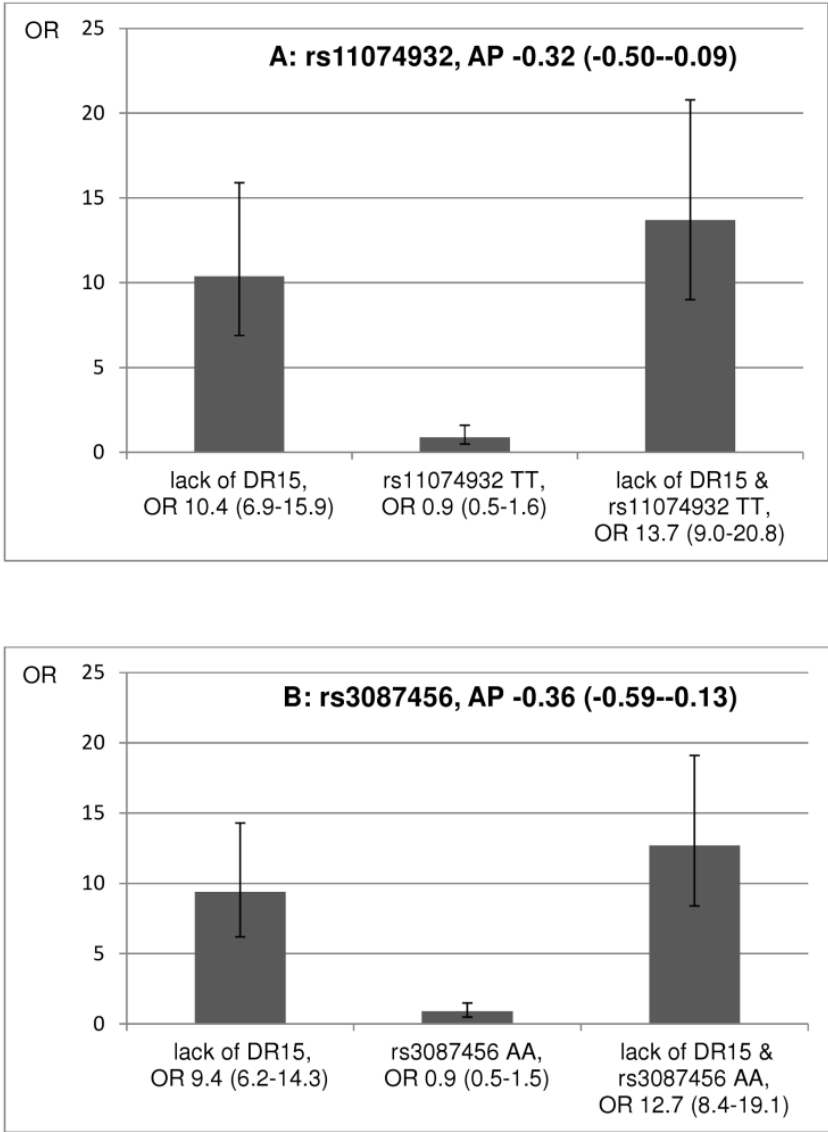
S1. SNP positions and association analysis for T1D in the DISS2 cohort.

\begin{tabular}{|c|c|c|c|c|c|c|c|}
\hline \multirow[t]{2}{*}{ SNP name } & \multirow[t]{2}{*}{ htSNP } & \multirow[t]{2}{*}{ Location/position ${ }^{1}$} & \multirow[t]{2}{*}{$\mathrm{H}-\mathrm{W}^{2}$} & \multicolumn{2}{|c|}{$\begin{array}{c}\text { Minor allele } \\
\text { frequency } \\
\text { in DISS2 }\end{array}$} & \multirow{2}{*}{$\begin{array}{c}\text { Association }^{3} \\
\mathrm{P}<\end{array}$} & \multirow[t]{2}{*}{$\begin{array}{c}\text { Association after } \\
\text { matching cases } \\
\text { and controls for } \\
\text { age }^{4}\end{array}$} \\
\hline & & & & patients & controls & & \\
\hline rs11074930** & na & Before PI/ 10842650 & ns & 0.45 & 0.52 & 0.005 & 0.04 \\
\hline rs10431908** & na & Before PI/ 10851548 & ns & 0.23 & 0.28 & 0.01 & 0.39 \\
\hline rs8052975** & na & Before PI/ 10856764 & ns & 0.26 & 0.30 & 0.02 & 0.44 \\
\hline rs4781003** & na & Before Pl/ 10859668 & ns & 0.16 & 0.19 & 0.1 & 0.60 \\
\hline rs7501308** & na & Before PI/ 10862957 & ns & 0.26 & 0.31 & 0.006 & 0.08 \\
\hline rs4781009* & No & Before PI/ 10865178 & ns & 0.26 & 0.30 & 0.04 & 0.32 \\
\hline rs7500908 & No & $\mathrm{Pl} / 10867491$ & $\mathrm{np}$ & - & - & - & - \\
\hline rs8059450 & No & $\mathrm{Pl} / 10867746$ & $\mathrm{np}$ & - & - & - & - \\
\hline rs6498114* & No & $\begin{array}{c}\text { between PI and PIII/ } \\
10871619\end{array}$ & ns & 0.22 & 0.26 & 0.03 & 0.16 \\
\hline rs6416647* & yes & $\begin{array}{c}\text { between PI and PIII/ } \\
10873098 \\
\end{array}$ & ns & 0.27 & 0.32 & 0.005 & 0.09 \\
\hline rs11074932* & No & $\begin{array}{c}\text { between PI and PIII/ } \\
10875837\end{array}$ & ns & 0.27 & 0.32 & 0.002 & 0.05 \\
\hline rs6498116* & No & $\begin{array}{c}\text { between PI and PIII/ } \\
10876783 \\
\end{array}$ & ns & 0.22 & 0.25 & 0.04 & 0.27 \\
\hline rs7404116 & No & $\begin{array}{c}\text { between PI and PIII/ } \\
10877836 \\
\end{array}$ & $\mathrm{np}$ & - & - & - & - \\
\hline rs2071170* & No & $\begin{array}{c}\text { between PI and PIII/ } \\
10878128\end{array}$ & ns & & & & \\
\hline rs3087456* & Yes & In PIII/ 10878403 & ns & 0.24 & 0.28 & 0.03 & 0.16 \\
\hline rs12928665* & No & $\begin{array}{c}\text { between PIII and PIV/ } \\
10878975\end{array}$ & ns & 0.22 & 0.25 & 0.06 & 0.28 \\
\hline rs12919717* & No & intron/ 10880686 & ns & 0.22 & 0.25 & 0.04 & 0.29 \\
\hline rs4781011* & Yes & intron/ 10882812 & ns & 0.24 & 0.27 & 0.06 & 0.22 \\
\hline rs11074933 & No & intron/ 10884067 & $\mathrm{np}$ & - & - & - & - \\
\hline rs11074934* $^{*}$ & No & intron/ 10886941 & ns & 0.26 & 0.28 & 0.17 & 0.16 \\
\hline rs10048113* & No & intron/ 10889417 & ns & 0.24 & 0.26 & 0.15 & 0.19 \\
\hline rs8043545 & No & intron/ 10889846 & $\mathrm{np}$ & - & - & - & - \\
\hline rs8062705 & No & intron/ 10892631 & $\mathrm{np}$ & - & - & - & - \\
\hline rs7195305* & No & intron/ 10894700 & ns & & & & \\
\hline rs11074937 & No & intron/ 10896875 & $\mathrm{np}$ & - & - & - & - \\
\hline rs4781015 & No & intron/ 10899453 & $\mathrm{np}$ & - & - & - & - \\
\hline rs7189406* & No & intron/ 10900989 & ns & & & & \\
\hline rs6498124* & Yes & intron/ 10903351 & ns & 0.44 & 0.44 & 0.92 & 0.1 \\
\hline rs11647384* & Yes & intron/ 10904790 & ns & 0.40 & 0.40 & 0.75 & 0.58 \\
\hline rs7404615* & No & intron/ 10907174 & ns & & & & \\
\hline rs4774* & Yes & non-synonymous/ 10908349 & ns & 0.32 & 0.30 & 0.35 & 0.23 \\
\hline rs2229319 & No & non-synonymous/ 10908823 & $\mathrm{np}$ & - & - & - & - \\
\hline rs7196089 & No & intron/ 10910602 & $\mathrm{np}$ & - & - & - & - \\
\hline rs4781019* & Yes & intron/ 10911651 & ns & 0.46 & 0.47 & 0.52 & 0.54 \\
\hline rs11074938* & Yes & intron/ 10914044 & ns & 0.36 & 0.36 & 0.99 & 0.44 \\
\hline rs11647308 & No & intron/ 10914145 & $\mathrm{np}$ & - & - & - & - \\
\hline rs4781021* & No & intron / 10916768 & ns & & & & \\
\hline rs6498131* & No & intron / 10918127 & ns & & & & \\
\hline rs8056269* & Yes & intron / 10920068 & $<0.0009$ & 0.44 & 0.42 & na & na \\
\hline rs7203275 & No & intron / 10924098 & $\mathrm{np}$ & - & - & - & - \\
\hline rs4781024* & No & intron / 10924559 & ns & & & & \\
\hline rs1139564* & Yes & untranslated / 10926123 & ns & 0.17 & 0.17 & 0.67 & 0.81 \\
\hline rs8052709* & Yes & untranslated / 10927756 & ns & 0.27 & 0.30 & 0.11 & 0.17 \\
\hline rs11643328 & No & untranslated / 10928828 & $\mathrm{np}$ & - & - & - & - \\
\hline rs3087519* & No & untranslated / 10930709 & ns & & & & \\
\hline rs4072865* & Yes & untranslated / 10931606 & ns & 0.48 & 0.49 & 0.43 & 0.47 \\
\hline rs12708716** & na & CLEC16A gene / 11087374 & ns & 0.28 & 0.32 & 0.07 & 0.07 \\
\hline
\end{tabular}

All SNPs were first genotyped in a selected cohort of 373 controls. 13 of the selected SNPs were non-polymorphic and 1 did not follow Hardy-Weinberg equilibrium and were discarded from further studies

* SNPs run in the HapBlock program. All markers within the haplotype blocks where not typed in the DISS cohort.

** SNPs added in second round of genotyping.

${ }^{1}$ Chromosome position, genome build 36.3, contig NT 010393.15 (Reference sequence)

${ }^{2}$ Test of Hardy-Weinberg Equilibrium in 373 Caucasian controls, $n s=p>0.05, n p=$ non-polymorphic

${ }^{3}$ Association analyses performed in Unphased using cocaphase command in the DISS2 cohort. After correcting for multiple

testing, significant association remained only for rs11074932.

${ }^{4}$ Association analyses performed in Unphased using cocaphase command in the DISS2 cohort after manually matching each case to one or if possible two controls by exact age. 
S2. LD block analysis in 373 Caucasian controls

\begin{tabular}{|c|c|c|c|c|c|c|}
\hline $\begin{array}{l}\text { Haplotype } \\
\text { Block No. }\end{array}$ & positions & $\begin{array}{c}\text { SNP } \\
\text { boundaries }\end{array}$ & $\begin{array}{l}\text { Block } \\
\text { size } \\
\text { (bp) }\end{array}$ & $\begin{array}{c}\text { Number } \\
\text { of } \\
\text { typed } \\
\text { SNPs }\end{array}$ & htSNPs & $\begin{array}{c}\% \text { of uniquely } \\
\text { distinguished } \\
\text { haplotypes }\end{array}$ \\
\hline Block 1 & $\begin{array}{l}\text { upstream of } \\
\text { PI to } \\
\text { between PI } \\
\text { and PIII }\end{array}$ & $\begin{array}{c}\text { rs4781009- } \\
\text { rs6416647 }\end{array}$ & $\begin{array}{l}7920 \\
\text { bp }\end{array}$ & 3 & rs6416647 & 89 \\
\hline Block 2 & $\begin{array}{l}\text { upstream of } \\
\text { Plll to } \\
\text { downstream } \\
\text { of exon } 8\end{array}$ & $\begin{array}{c}\text { rs11074932 } \\
- \\
\text { rs6498124 }\end{array}$ & $\begin{array}{c}27514 \\
b p\end{array}$ & 12 & $\begin{array}{l}\text { rs3087456 / } \\
\text { rs4781011 / } \\
\text { rs6498124 }\end{array}$ & 81 \\
\hline Block 3 & $\begin{array}{l}\text { upstream of } \\
\text { exon } 11 \text { to } \\
\text { exon } 13 \\
\end{array}$ & $\begin{array}{c}\text { rs11647384 } \\
\text { - rs4774 }\end{array}$ & $\begin{array}{c}3559 \\
\text { bp }\end{array}$ & 4 & $\begin{array}{c}\text { rs11647384 / } \\
\text { rs4774 }\end{array}$ & 88 \\
\hline Block 4 & $\begin{array}{l}\text { the end of } \\
\text { exon } 13 \text { to } \\
\text { exon } 20 \\
\end{array}$ & $\begin{array}{c}\text { rs4781019 - } \\
\text { rs8056269 }\end{array}$ & $\begin{array}{c}8417 \\
b p\end{array}$ & 5 & $\begin{array}{c}\text { rs4781019 / } \\
\text { rs11074938 / } \\
\text { rs8056269 } \\
\end{array}$ & 87 \\
\hline Block 5 & $\begin{array}{l}\text { spans the } \\
\text { 3'UTR. }\end{array}$ & $\begin{array}{c}\text { rs1139564 - } \\
\text { rs4072865 }\end{array}$ & $\begin{array}{c}5483 \\
\text { bp }\end{array}$ & 4 & $\begin{array}{c}\text { rs1139564 / } \\
\text { rs8052709 / } \\
\text { rs4072865 } \\
\end{array}$ & 94 \\
\hline
\end{tabular}

LD block definition and htSNP identification was carried out in HapBlock program (24-26). The block partitioning algorithm used was the dynamic programming algorithm by Zhang et al (24) this minimizes the total number of tag SNPs in a region of interest. The method for block partitioning was the "common haplotype" method where a set of SNPs form a LD block if the common haplotypes in this block account for at leas $80 \%$ of the observed haplotypes. The method for identifying htSNPs was the "all common haplotypes" method. This method identifies the minimum set of SNPs that can distinguish all common haplotypes within an LD block. Common haplotypes were defined to have a frequency of $5 \%$ or more. 
S3. Cohorts

a) Overview of T1D cohorts $-\mathrm{n}(\%)$

\begin{tabular}{|c|c|c|c|c|c|c|}
\hline controls & BDD & DISS1 & DISS2 & DR & SV2 & Total sum: \\
\hline total & 0 & 348 & 797 & 2312 & 342 & 3799 \\
\hline men & 0 & $196(56 \%)$ & $448(56 \%)$ & $1695(73 \%)$ & $179(52 \%)$ & 2518 \\
\hline women & 0 & $152(44 \%)$ & $349(44 \%)$ & $617(27 \%)$ & $163(48 \%)$ & 1281 \\
\hline mean age & 0 & 25 & 25 & 63 & 10 & \\
\hline median age & 0 & 24 & 26 & 63 & 11 & \\
\hline range yrs & 0 & $15-34$ & $15-36$ & $45-74$ & $1-15$ & \\
\hline cases & BDD & DISS1 & DISS2 & DR & SV2 & \\
\hline total & 1475 & 431 & 544 & 631 & 404 & 3485 \\
\hline men & $844(57 \%)$ & $277(64 \%)$ & $349(64 \%)$ & $337(53 \%)$ & $213(53 \%)$ & 2020 \\
\hline women & $631(43 \%)$ & $154(36 \%)$ & $195(36 \%)$ & $294(47 \%)$ & $191(47 \%)$ & 1465 \\
\hline mean age & 10 & 25 & 24 & 22 & 8 & \\
\hline median age & 10 & 25 & 25 & 21 & 9 & \\
\hline range yrs & $0-18$ & $15-36$ & $15-35$ & $0-70$ & $1-14$ & \\
\hline
\end{tabular}

b) Summary of cohorts used for age-stratification analyses; controls only, age 0-91 yrs (n).

\begin{tabular}{|c|c|c|c|c|c|c|c|c|c|}
\hline marker & DISS1 & DISS2 & SV2 & DR & MS & RA & MI & AD & Total sum: \\
\hline rs11074932 & 295 & 757 & 191 & na & 1177 & 942 & 385 & na & 3747 \\
\hline rs3087456 & 207 & 751 & 331 & 2312 & 1602 & 1324 & 387 & 417 & 7331 \\
\hline rs4774 & 204 & 777 & 329 & na & 477 & 738 & 386 & 406 & 3317 \\
\hline
\end{tabular}

c) Summary of population based control cohorts for replication of age variation (n).

\begin{tabular}{|c|c|c|c|}
\hline marker & OPRA 75 yrs old & PEAK 25 yrs old & Total sum: \\
\hline rs11074932 & 1002 & 1002 & 2004 \\
\hline rs3087456 & 994 & 993 & 1987 \\
\hline rs4774 & 990 & 976 & 1966 \\
\hline
\end{tabular}




\section{S4. Members of the Swedish Childhood Diabetes Study Group:}

All from Departments of Pediatrics in Sweden: M. Aili, Halmstad; L.E. Bååth, Östersund; E.

Carlsson, Kalmar; H. Edenwall, Karlskrona; G. Forsander, Falun; B.W. Granström, Gällivare;

I. Gustavsson, Skellefteå; R. Hanås, Uddevalla; L. Hellenberg, Nyköping; H. Hellgren, Lidköping; E. Holmberg, Umeå; H. Hörnell, Hudiksvall; Sten-A. Ivarsson, Malmö; C. Johansson, Jönköping; G. Jonsell, Karlstad; K. Kockum, Ystad, B. Lindblad, Mölndal; A. Lindh, Borås; J. Ludvigsson, Linköping; U. Myrdal, Vä sterås; J. Neiderud, Helsingborg; K. Segnestam, Eskilstuna; S. Sjöblad, Lund;L. Skogsberg, Boden; L. Strömberg, Norrköping; U. Ståhle, Ängelholm; B. Thalme, Huddinge; K. Tullus, Danderyd; T. Tuvemo, Uppsala; M. Wallensteen, Stockholm; O. Westphal, Göteborg; and J. Åman, Örebro.

\section{Members of the Diabetes Incidence in Sweden Study (DISS) Group:}

Hans Arnqvist, Department of Internal Medicine, University of Linköping, Linköping; Elisabeth Björck, Department of Medicine, University Hospital, Uppsala; Jan Eriksson, Department of Medicine, University of Umeå, Umeå; Lennarth Nyström, Department of Epidemiology and Public Health, University of Umeå, Umeå; Lars Olof Ohlson, Sahlgrenska Hospital, University of Göteborg, Göteborg; Bengt Scherstén, Department of Community Health Sciences, Dahlby, University of Lund, Lund; Jan Östman, Center for Metabolism and Endocrinology, Huddinge University Hospital, Stockholm.

\section{Members of the BDD Study Group:}

Anita Nilsson (Malmö), Helena Desaix (Borås), Kalle Snellman (Eskilstuna), Anna

Olivecrona (Falun), Åke Stenberg (Gällivare), Lars Skogsberg (Gävle), Nils Östen Nilsson (Halmstad), Jan Neiderud (Helsingborg), Åke Lagerwall (Hudiksvall), Kristina Hemmingsson (Härnösand), Karin Åkesson (Jönköping), Göran Lundström (Kalmar), 
Magnus Ljungcrantz (Karlskrona), Eva Albinsson (Karlstad), Karin Larsson (Kristianstad), Christer Gundewall (Kungsbacka), Rebecka Enander (Lidköping), Agneta Brännström (Luleå), Maria Nordwall (Norrköping), Lennart Hellenberg (Nyköping), Elena Lundberg (Skellefteå), Henrik Tollig (Skövde), Britta Björsell (Sollefteå), Björn Rathsman (Stockholm/Sacchska), Torun Torbjörnsdotter (Stockholm/Huddinge), Björn Stjernstedt (Sundsvall), Nils Wramner (Trollhättan), Ragnar Hanås (Uddevalla), Ingemar Swenne (Uppsala), Anna Levin (Visby), Anders Thåström (Västervik), Carl-Göran Arvidsson (Västerås), Stig Edvardsson (Växjö), Björn Jönsson (Ystad), Torsten Gadd 